\author{
Problematicity of emotion in modern \\ aesthetics. Denials and alternatives
}

\title{
Problematicidad de la emoción en la estética moderna. Negaciones y alternativas
}

Fernando Infante del Rosal

Universidad de Sevilla finfante@us.es

DOI: https://doi.org/10.15366/bp.2020.24.018

Bajo Palabra. II Época. No 24. Pgs: 361-384

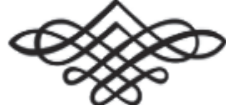


Recibido: 13/03/2020

Aprobado: 12/08/2020

\section{Resumen}

La condición problemática de la emoción en la estética moderna está unida al ideal de la autonomía del arte. En Kant aparece formulada esa problematicidad, que pertenece al marco estético moderno y que se traspasa al contemporáneo. Tras analizar las formulaciones, de Kant, Diderot, Schiller, Schleiermacher y Hegel principalmente, se propone una caracterización de las tres vías de negación o inhibición de la emoción y de sus respectivas alternativas en la estética y en el arte del siglo XX.

Palabras clave: Estética, emoción, sentimiento, Diderot, Kant, Schiller, Schleiermacher, Hegel, Adorno.

\section{Abstract}

The problematic condition of emotion in modern aesthetics is linked to the ideal of the autonomy of art. This uncertain character, which belongs to the modern aesthetic framework and which is transferred to the contemporary one, appears in Kant's systematic thought. After analyzing the formulations, mainly from Kant, Diderot, Schiller, Schleiermacher and Hegel, a characterization of the three ways of negation or inhibition of emotion and their respective alternatives in aesthetics and art of the 20th century is proposed.

Keywords: Aesthetics, emotion, feeling, Diderot, Kant, Schiller, Schleiermacher, Hegel, Adorno. 


\section{Introducción}

La EMOción, entendida como ese tipo de estados intensos y pasajeros del ánimo que van acompañados generalmente de cierta conmoción somática, adquiere en la estética moderna un carácter problemático. Esta inconveniencia de la emoción -en la experiencia artística - no es sin embargo una denuncia exclusiva de la Modernidad: su presencia intermitente en el pensamiento estético occidental y en la apreciación artística a través de los siglos parece estar motivada por el carácter de problema con el que se presenta ya en La República, si bien contrarrestado persistentemente por la condición de elemento primordial con la que aparece en la Poética.

Ahora bien, si tradicionalmente la crítica a la emoción en el arte se había hecho desde fuera de la producción artística, ahora, eran la propia práctica artística y la reflexión dirigida a ella las que la ponían en cuestión. La tradicional denuncia de la emoción en el arte había estado casi siempre impulsada por razones extra-artísticas - por desviar la finalidad ética, religiosa, política, etc. hacia un estado de placer (o aparente displacer) ajeno a dichos fines- $\mathrm{y}$ a instancias de instituciones promotoras de un arte a su servicio, no por parte de los artistas. Precisamente porque las instituciones éticas, religiosas o políticas han sido siempre conscientes del factor adherente de la emoción, han pretendido usualmente ejercer un control sobre las emociones representadas y suscitadas en aquello que generalmente llamamos arte. Las emociones ajenas a esa direccionalidad eran tachadas de distracción a la correcta finalidad, cuando no de peligro. Piénsese por ejemplo en la bula de 1322 con la que Juan XXII condenaba el Ars Nova por su complejidad y por el olvido de la devoción que debería perseguir el canto litúrgico.

Pero la problematicidad de la emoción en la estética moderna no guarda continuidad con aquella heteronomía tradicional de lo artístico, guiada por fines externos a un dominio o práctica, sino por lo contrario, por la defensa de su autonomía, de su separación respecto de aquellos fines. No se trata de que las emociones puedan corromper las finalidades éticas, religiosas o políticas del arte, como de que la emoción desvíe al arte de su propia finalidad. Si bien el arte moderno no renuncia a aquellas finalidades, ahora las emprende desde su autonomía; su emancipación es la condición básica para una nueva y centrífuga entrega a la función. Por eso, en Brecht o en Adorno, la emoción no es solo un problema que aluda al arte en tanto que fait social, sino en tanto que arte. La emoción es la ropa sucia que ha de lavarse en casa. 
La crítica heterónoma a la emoción en el arte había estado dirigida por su ruptura con la convenientia, que establecía una relación pactada entre lo "estético" y lo "ético", entre las formas de la representación y lo representado, o del medio y el contenido si se quiere; la crítica autónoma toma a la emoción como dilema y desafío por su capacidad para consolidarse como elemento central de las experiencias estética y artística, algo que atenuaría otros factores de dichas experiencias, o disolvería lo que de específico podría haber en ellas.

La problematicidad de la emoción en la estética moderna está, por tanto, en estrecha unión con la autonomía como ideal y como valor. La autonomía del arte y de la estética como ámbitos, y de lo artístico y de lo estético como experiencias, presupone, por una parte, la determinación de una identidad, de una entidad y de una especificidad -la de esos ámbitos y experiencias, alumbrados en la Modernidad como característicos-, y, por otra, el señalamiento de un ideario y un programa de emancipación de tales identidades frente a las instancias que las han condicionado históricamente. La determinación de la especificidad constituye el aspecto positivo de la autonomía, y el recorrido emancipatorio, su aspecto negativo. A grandes rasgos podría reconocerse el primero en la crítica kantiana y el segundo en la lectura schilleriana. De esta manera, la autonomía se mide en la relación dialéctica existente entre identidad y libertad.

Ante esto cabría preguntarse en qué medida la estética como disciplina ha contribuido a determinar la identidad de esos ámbitos y experiencias, y en qué medida ha servido para diseñar el programa de emancipación del arte; en qué función se ha empeñado con más fuerza, si en la identitaria o en la programática. A mi juicio, la estética, como disciplina reflexiva, filosófica y académica, no ha servido tanto a la determinación de la identidad del arte y de lo estético, como a la detección de los factores extra-artísticos y extra-estéticos y a la consolidación de las fórmulas emancipatorias (en Adorno, especialmente). Y esto es debido en gran medida a un hecho: la especificidad de lo artístico vislumbrada en la Modernidad implica paradójicamente -como ha afirmado Rancière- el descubrimiento de una inespecificidad ${ }^{1}$, en la medida en que el arte puede estar en todo y en tanto que ya no se identifica con modos de hacer. Además, una gran parte del pensamiento estético se ha centrado, más que en la determinación de la identidad de lo artístico, en la búsqueda de la esencialidad; más en la identidad sustancial, diríamos, que en la identidad formal del arte.

Así, la estética ha señalado históricamente aquellos factores respecto a los cuales el arte debía proclamar su emancipación o su soberanía. Así se han ido configu-

${ }^{1}$ Cf. Rancière, J., El malestar en la estética, Madrid, Clave Intelectual, 2012. 
rando los distintos sentidos de la autonomía: independencia de la obra y del acto artístico respecto a la realidad; desinterés y separación de la razón instrumental; independencia respecto a la moral; exclusión del placer extraestético; libertad del juicio de gusto; liberación de la forma; autosuficiencia a la manera del arte por el arte; independencia del creador respecto del receptor; autonomía del arte frente a la cultura; y exclusión de la emoción extraestética. Este artículo pretende analizar la manera en que se ha formulado esta última vía de la autonomía del arte y de lo estético. Para ello partiré de un análisis del estatuto de la emoción, el sentimiento y la pasión en la Crítica del juicio de Kant, extendido al contexto ilustrado y del primer romanticismo, porque es aquí donde se expresan y se formulan de manera sistemática las inquietudes acerca de la emoción que formarán parte del régimen estético característico de lo moderno y lo contemporáneo. Una vez presentado este suelo, definiré las tres vías de negación de la emoción, así como sus respectivas alternativas, en la estética y en el arte desde la Modernidad.

\section{La emoción en la Crítica del Juicio}

LA CARACTERIZACIÓN PROBLEMÁTICA de la emoción en la estética moderna encuentra su primera formulación en la obra fundacional del pensamiento estético sistemático, la Crítica del Juicio de Kant. Todas las formas modernas y contemporáneas de negación de la emoción en el arte encuentran allí su origen formulario, si bien el filósofo alemán enuncia solo una parte de ellas: será el kantismo el que las desarrolle y las exprese de manera explícita.

Kant precisa la naturaleza del puro juicio de gusto como aquel "sobre el cual encanto y emoción no ejercen influjo alguno (aunque se dejen éstos enlazar con la satisfacción de lo bello), y que tiene, pues, solo la finalidad de la forma como fundamento de determinación." ${ }^{2}$ La emoción (aquí Rührung), como el encanto, vendría a ser una "satisfacción empírica" ${ }^{3}$ que al mezclarse con aquella pureza la dirigiría a un lugar distinto del de la experiencia contemplativa de la belleza.

Es necesario aclarar que para Kant la emoción (Rührung o Affekt) es fundamentalmente una afección orgánica privada de contenido cognitivo -aunque precedida y seguida de representaciones ${ }^{4}$-, a diferencia del sentimiento (Gefühl), que designa-

\footnotetext{
${ }^{2}$ Kant, I., Critica del Juicio, Madrid, Austral, 1999, p. 157 / Kant, I., Kritik der Urteilschaft, Köln, Anaconda Verlag, 2015 (asimilada a Gesammelte Schriften, Berlin, Preussische Akademie der Wissenschaften, vol. 1-22). $(\mathrm{KU} \$ 13, \mathrm{AA} 05)$ p. 223.

3 Ibid., p. 157 / (KU $\$ 14$, AA 05) p. 224.

${ }^{4}$ Vid. González, A. M., "Emoción, Sentimiento y Pasión en Kant", en Trans/Form/Ação vol. 38 no.3 Marília sept./ dec. 2015, pp. 75-98.
} 
ría en un sentido más amplio la dimensión subjetiva de la experiencia, no limitada a la sensación empírica. En este sentido, el Kant de la Crítica del Juicio mantiene, al menos parcialmente, la valoración del sentimiento propia de su etapa precrítica y enlaza con la tradición moderna: como dice Shiner, "muchos autores, entre ellos Hume, Diderot, Rousseau y Sulzer, no sólo distinguían el sentimiento de la sensualidad y de la emoción, sino que también lo unían a la razón en una especie de conocimiento tácito o espontáneo que sugería un tercer tipo de experiencia donde se combinaban elementos de ambos." 5

En los manuscritos "Praktische Philosophie Powalski" Kant había afirmado que la naturaleza nos dota de sentimiento (Gefühl) e inclinaciones (Neigungen), no de emociones (Affekten) y pasiones (Leidenschaften): "el hecho de que el sentimiento escale hasta la emoción procede de la disposición del sujeto, y el que la inclinación se convierta en pasión procede de la sensibilidad ciega de los seres humanos, que no saben gobernarse a sí mismos." "En la Crítica del Juicio la problematicidad atañe a la emoción (Rührung o Affekt), no al sentimiento (Gefühl): "no siendo, sin embargo, la belleza -dice Kant-, sin relación con el sentimiento del sujeto, nada en sí [da doch Schönheit ohne Beziehung auf das Gefühl des Subjekts für sich nichts ist]."7

En cambio, la emoción (Rührung), "sensación [Empfindung] en donde el agrado se produce sólo mediante una momentánea suspensión y un desbordamiento posterior más fuerte de la fuerza vital, no pertenece en modo alguno a la belleza." ${ }^{8} \mathrm{La}$ emoción parece retener a la experiencia en el ámbito de la afección empírica y en el placer que implica su peculiar vivificación, y, aunque es capaz de intensificar la actividad psíquica y de fomentar representaciones, se desvincula de la pretensión de validez universal que caracteriza el sentimiento estético. La emoción permanece en el dominio empírico de la sensación y del placer y procede de manera inversa a la parte cognitiva de la experiencia estética. Incluso el arte estético puede ser agradable o bello según la experiencia y el juicio se mantengan en el nivel de la sensación o en el del conocimiento respectivamente: "Es el primero cuando el fin es que el placer acompañe las representaciones como meras sensaciones; es el segundo cuando el fin es que el placer acompañe las representaciones como modos de conocimiento." 9

Es importante considerar que, en la Analitica de lo bello, Kant habla principalmente de la emoción como elemento de la experiencia subjetiva -y receptiva- de lo bello, no como factor expresivo del artista o del objeto, sea natural o artístico. En

\footnotetext{
5 Shiner, L., La invención del arte, Barcelona, Paidós, 2004, p. 201.

${ }^{6}$ Kant, I., "Praktische Philosophie Powalski", en Gesammelte Schriften, Göttingen/Berlin, Akademie der Wissenschaften, 1900 (V-PP/Powalski [1782-83], AA 27) pp. 204-205.

7 Kant, I., Crítica del Juicio, op. cit., p. 150 / (KU, \$9, AA 05) p. 218.

${ }^{8}$ Ibid., p. 160 / (KU \$ 14, AA 05) p. 226.

9 Ibid., p. 260 / (KU \$ 44, AA 05) p. 305.
} 
la estructura subjetiva, el juicio estético es en cierto modo independiente, diríamos, de la diferencia empírica y lógica entre creación y contemplación. A pesar de esto, la estética kantiana influirá significativamente en las teorías expresivistas contemporáneas.

En la experiencia de lo sublime la emoción cobra una intensidad mayor y, aun siendo mera afección orgánica, parece favorecer más abiertamente el conocimiento y la aprehensión del límite propia de la sublimidad; la conmoción que implica opera en la dirección de ese sentimiento de desbordamiento y no parece remitir a sí misma como finalidad tan abiertamente como hace en lo bello. Por otra parte, la emoción que interviene en la experiencia de lo sublime es presentada con mayor gravedad: lo sublime, dice Kant, "[...] como emoción, parece ser, no un juego, sino seriedad en la ocupación de la imaginación.” ${ }^{10}$ Podría pensarse que la emoción resulta más útil en el contexto de desbordamiento e intensidad propio de lo sublime porque contribuye con su propia vehemencia, pero, como en la experiencia de lo bello, tampoco aquí es el elemento definitorio, y, en cualquier caso, lo sublime no se reduce a la emoción. La fórmula de las Observaciones sobre el sentimiento de lo bello y lo sublime "Lo sublime conmueve [emociona], lo bello encanta [Das Erhabene rührt, das Schöne reizt]" ${ }^{11}$ se ve ahora matizada por una relación circunstancial entre lo sublime y la emoción: lo sublime emociona a veces ${ }^{12}$. Kant llega a afirmar que "[...] la falta misma de emoción [Affektlosigkeit] (apatheia, phlegma, in significatu bono) de un espíritu que sigue enérgicamente sus principios inmutables es sublime, y en modo mucho más excelente, porque tiene de su parte al mismo tiempo la satisfacción de la razón pura." ${ }^{13}$ La clave de esta afirmación puede estar en el hecho de que, en Kant, lo sublime tampoco se reduce al ámbito estético.

Ahora bien, hay un pasaje de la Crítica del Juicio, la Nota general a la exposición de los juicios estéticos reflexionantes, que guarda una gran importancia en la delineación que hace Kant de la emoción. El pensador usa ahora dos términos para referirse a las emociones, Rührungen y Affekten, pero lo hace con un matiz diferente en cada uno. Affekt aparece como una intensificación de Rührung: "De ahí que las emociones [Rührungen], que pueden crecer en fuerza hasta la emoción [Affekt], sean también muy diferentes. [Dahe sind die Rührungen, welche bis zum

\footnotetext{
$\overline{10}$ Ibid., p. 184 / (KU $\$ 23$, AA 05) p. 245.

11 Kant, I., Observaciones sobre el sentimiento de lo bello y lo sublime, Madrid, Fondo de Cultura Económica, 2005, p. 5 / Kant, I., Beobachtungen über das Gefühl des Schönen und Erhabenen (GSE), en Gesammelte Schriften, Berlin, Preussische Akademie der Wissenschaften (vol. 02), 1912, p. 209.

12 Park, K. H., Kant über das Erhabene: Rekonstruktion und Weiterführung der kritischen Theorie des Erhabenen Kants, Würzburg, Königshausen and Neumann, 2009, p. 63

13 Kant, I., Crítica del Juicio, op. cit., p. 219 / (KU \$29 Allg. Anm., AA 05) p. 272.
} 
Affekt stark werden können, auch sehr verschieden]. ${ }^{14}$ Este pasaje plantea problemas a los traductores, que se ven obligados a diferenciar ambos términos usando analogías igualmente diferenciadas ${ }^{15}$. Pero, aunque no dispongamos de términos afines en castellano, lo que parece claro es que Kant, que ha usado el término Rührung al hablar de lo bello, está indicando que en el ámbito de lo sublime tal emoción puede alcanzar una dimensión diferente: "Se tienen emociones [Rührungen] valerosas y se tienen tiernas. Estas últimas cuando crecen hasta la emoción [Affekt], no sirven para nada; la inclinación a ellas se llama sensiblería. [Man hat mutige, man hat zärtliche Rührungen. Die letzteren, wenn sie bis zum Affekt steigen, taugen gar nichts; der Hang dazu heißt die Empfindelei]." ${ }^{16}$ Según Kant, hay ciertas emociones (gewisse Affekten) que podríamos llamar sublimes en tanto que se presentan como una fuerza del espíritu que supera ciertos obstáculos de la sensibilidad. Así sucede con el entusiasmo, que puede ser considerado sublime estéticamente, pero no respecto del bien intelectual, porque, como toda emoción (Affekt), también esta "es ciega" ${ }^{17}$ y no merece la satisfacción de la razón. El entusiasmo es estéticamente sublime porque implica un impulso más fuerte y duradero del espíritu, es "la idea del bien con emoción [Affekt]" ${ }^{18}$, pero esta no solo contribuye al placer del bien, sino que remite al suyo propio.

En este apartado introduce Kant una nota que resulta muy esclarecedora del doble nivel de emoción que implican Rührung y Affekt:

Las emociones [Affekten] se distinguen específicamente de las pasiones [Leidenschaften]. Aquéllas se refieren sólo al sentimiento [Gefühl]; éstas pertenecen a la facultad de desear, y son inclinaciones que dificultan o imposibilitan toda determinabilidad de la voluntad mediante principios; aquéllas son tormentosas y sin premeditación; éstas, perseverantes y reflexivas. Así, la indignación, como cólera, es una emoción; pero como odio (deseo de venganza), es una pasión. Esta última no puede nunca y en ninguna relación ser llamada sublime, porque en la emoción la libertad del espíritu queda, desde luego, suspendida, pero en la pasión es anulada. ${ }^{19}$

\footnotetext{
${ }^{14}$ Ibid., p. 219 / (KU \$29 Allg. Anm., AA 05) p. 273. Traduzco aquí Rührungen como "emociones" en lugar de "sentimientos" por lo que se indica en la siguiente nota.

15 Así, García Morente (Crítica del Juicio, op. cit.), que había traducido Rührung como "emoción” en los pasajes precedentes, cambia ahora a "sentimiento" para distinguirlo de Affekt, que sigue traduciendo como "emoción", no diferenciando Rührung de su traducción de Gehful. Por su parte, Aramayo y Mas (Kant, I.; Crítica del discernimiento, Madrid, Antonio Machado, 2019) deciden traducir siempre Affekt como "afecto" y Rührung como "emoción", pero no resulta clara cuál es la naturaleza de ese "afecto" que se presenta aquí como un grado más de la "emoción".

${ }^{16}$ Kant, I., Crítica del Juicio, op. cit., p. 219 / (KU \$29 Allg. Anm., AA 05) p. 273. También aquí traduzco Rührungen como "emociones" a diferencia de García Morente.

17 Ibid., p. 218 / (KU \$29 Allg. Anm., AA 05) p. 272.

18 Ídem.

19 Ibid., nota al pie.
} 
En la emoción, es la "libertad del espíritu" lo que se suspende. Esa libertad afectaría al "libre juego" de la imaginación y el entendimiento en la experiencia de lo bello, y a la actividad de la razón en lo sublime. Es evidente que la emoción intensa no alcanza el grado de negatividad de la pasión, que es un estado "perseverante", no pasajero como aquella.

Podría decirse que en lo bello el sentimiento [Gefühl] puede escalar hasta la emoción [Rührung], así como en lo sublime esta puede fortalecerse como emoción intensa $[A f f e k t]$, sin que en ningún caso esos tres niveles de la afectividad sean privativos del ámbito estético. Ambas transposiciones -de Gefühl a Rührung y de Rührung a Affekt- se dan como un crecimiento de la fuerza del espíritu que distorsiona, en el caso de lo bello, un sentimiento y, en el de lo sublime, también una emoción. Lo paradójico es que ese fortalecimiento y esa intensificación implican un retroceso, una fuerza inversa: en el caso de lo bello, desde el sentimiento hacia la sensación, o desde la propia experiencia de lo bello hacia la de lo agradable; en el caso de lo sublime, desde la violencia que la razón ejerce sobre la sensibilidad, a la sensibilidad misma, o desde la cercanía a la satisfacción intelectual y el bien, hacia una satisfacción que Kant considera negativa por meramente estética ${ }^{20}$. Pero, junto con ese movimiento hacia atrás, la emoción también implica un avanzar en exceso, un aceleramiento que sobrepasa la experiencia estética. La emoción se mueve, se desplaza respecto de un área que sería la propia de lo estético.

Ahora bien, para Kant la emoción no es problemática por sí misma, como no lo es ninguna afección y ninguna sensación. Existe en la actualidad una lectura que tiende a superar la imagen de un pensador enemistado con el orden de lo emocional ${ }^{21}$. No obstante, es imprescindible separar en Kant sentimiento de emoción, especialmente el sentimiento de placer (Gefühl der Lust), que juega un papel primordial en sus Críticas. El aspecto negativo no lo alcanza la afectividad en su conjunto, solo las emociones y las pasiones en tanto que echan a perder (verdirbt) el sentimiento y la inclinación, respectivamente.

El sentimiento, pues, no solo no es cuestionable, sino que está en la base del conocimiento y de la vida, y está asociado al cuerpo:

[...] porque la vida, sin sentimiento del órgano corporal, es sólo conciencia de la propia existencia, pero no sentimiento del bienestar o malestar, es decir, de la excitación [Beför-

${ }^{20}$ Cf. Ibid., p. 217 / (KU $\$ 29$ Allg. Anm., AA 05) p. 271.

${ }^{21}$ Vid. Sherman, N., The fabric of character, Oxford, Oxford University Press, 1989; Baron, M., Kantian Ethics almost without Apology, Ithaca, Cornell U.P., 1999; Louden, R. Kant's impure Ethics. Oxford, Oxford University Press, 2002; Kosgaard, C., Self-Constitution: agency, identity and integrity, Oxford, Oxford University Press, 2009; Cohen, A. (ed.)., Kant on emotion and value, London, Palgrave McMillan, 2014; Sánchez Madrid, N., "Resonancias emocionales de la razón en Kant”, en Princípios Revista de Filosofia, Natal, v. 23, n. 41 maio-ago. 2016, pp. 33-74. 
derung], de la suspensión [Hemmung] de las facultades vitales, pues el espíritu, por sí solo, es todo vida (el principio mismo de la vida), y las resistencias, las excitaciones [Hindernisse oder Beförderungen], hay que buscarlas fuera de él, y, sin embargo, en el hombre mismo, por lo tanto, en la unión con su cuerpo. ${ }^{22}$

La emoción asoma cuando esos obstáculos [Hindernisse] y esas excitaciones [Beförderungen] se intensifican y provocan una suspensión de la libertad del espíritu. Resulta evidente entonces que lo emocional no se vuelve problemático únicamente en el ámbito estético, sino en la vida general del espíritu. La emoción puede arruinar el sentimiento estético como puede hacerlo con los demás sentimientos, solo que en la experiencia de lo bello parece instalarse además como centro de dicha experiencia, dificultando tanto la apreciación como la vivencia misma de su singularidad. La emoción entorpece, no solo la comprensión de lo estético, sino su ejercicio. El primer problema de la emoción con el que Kant se enfrenta en la Crítica del Juicio y que intenta resolver de entrada es su fácil e impensada identificación con lo estético, no únicamente como un ingrediente más, sino como componente esencial. Son la fuerza y la intensidad de la emoción las que nos llevan frecuentemente a considerarla y a vivirla como el núcleo de lo estético (así sucedía en una gran parte de la sensibilidad empfindsamkeit de su época, y también en la opinión pública de nuestros días).

En resumen, en la Crítica del Juicio la emoción aparece presentada y singularizada como un componente problemático de la experiencia estética de las siguientes maneras:

1. En primer lugar, la emoción es una vivencia característica, comprendida fuera y antes de la experiencia estética que, al contribuir en el dominio estético, diluye la especificidad de dicho dominio. Interviene en lo estético, pero no es definitoria de su ámbito. Es un factor concomitante y frecuente en la experiencia de lo bello -"se deja relacionar", dice Kant-, pero ella misma, como el agrado, es ajena a la especificidad del puro juicio de gusto. La emoción no define lo propio de la experiencia de lo bello, tampoco de lo sublime en su totalidad.

2. En segundo lugar, como afección placentera o dolorosa ligada a la sensación empírica, interfiere en aquello que define el juicio estético, su particular modo de conocimiento determinado por la relación entre el juego libre de la imagi-

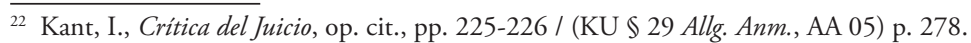


nación y la legalidad del entendimiento. En lo bello, desvía toda direccionalidad al entendimiento, y en lo sublime todo acceso a la razón, remitiendo lo estético al dominio de la sensación.

3. También, al poner el acento en la experiencia privada y particular del sujeto, intercepta la pretensión de universalidad (subjetiva) inherente al juicio estético. La emoción retiene a la experiencia estética en lo agradable, impidiendo que se dé como juicio de lo bello. Resulta significativo que Kant no hable de la emoción cuando aborda la comunicabilidad del juicio estético, a pesar de formar parte aquella de la estructura subjetiva.

4. Como movimiento intenso de la vida psíquica se inmiscuye en la acción del resto de factores de la experiencia estética aminorando su fuerza. Su intensidad entra en conflicto con el resto de elementos, lo que hace que termine apoderándose muchas veces del espacio de lo estético y convirtiéndose en el componente principal.

5. Finalmente, como satisfacción empírica invierte la dirección hacia la satisfacción universal y necesaria propia de lo bello, y obstaculiza la finalidad sin fin del puro juicio de gusto al poner el fin en sí misma. Por ser interesada, echa a perder (verdirbt) la imparcialidad del juicio de gusto.

Localizar el eco de estas formulaciones en los textos de Greenberg, Wöllflin, Panofsky, Adorno o Danto es fácil porque la referencia es expresa, pero es posible llegar más lejos afirmando que la estética kantiana ha influido en las interacciones disciplinarias entre la filosofía, las artes visuales y la historia del arte ${ }^{23}$. Por una parte, puede defenderse que sus fórmulas han tenido una influencia directa o indirecta -especialmente a través de Hegel y de Nietzsche- sobre la práctica y el pensamiento artísticos (por ejemplo, en Mondrian); por otra, es posible entender que Kant aborda un contexto reflexivo que él no ha producido: como dice Rancière, "los filósofos, a partir de Kant, tienen la tarea de pensar dicho régimen. Pero no lo han creado" ${ }^{24}$, lo cual haría irrelevante la crítica que Bourdieu dirige al filósofo alemán ${ }^{25}$.

Lo que resulta claro, no obstante, es que las formulaciones de la emoción en la Crítica del Juicio están unidas a un factor determinante en la comprensión y deve-

\footnotetext{
${ }^{23}$ Cheetham, M. A., Kant, Art, and Art History: Moments of Discipline, New York, Cambridge University Press, 2001, p. 23

${ }^{24}$ Rancière, J., El malestar en la estética, op. cit. p. 17.

25 Vid. Bourdieu, P., La distinción. Criterios y bases sociales del gusto, Madrid, Taurus, 2016.
} 
nir del arte desde entonces: su autonomía, tanto en lo que atañe a la especificidad, como al proyecto de emancipación propio de lo estético y, especialmente, de lo artístico. Es posible afirmar que, aunque Kant no hubiera precisado sistemáticamente la manera en que la emoción opera en lo estético, la aprehensión misma de la autonomía como señal o como valor lo implicarían en cualquier otro pensamiento que precisara dicha autonomía como ideal.

\section{La emoción y la sensibilidad estética}

No obstante, CON EL CUADRo que presenta Kant no se define completamente el sustrato crítico de la emoción en la primera Modernidad. Por eso, antes de pasar a presentar las vías modernas y contemporáneas de negación de la emoción, es conveniente apuntar al menos otros dos aspectos fundamentales de la consideración de la afectividad en la estética moderna de los que el pensamiento de Kant participaba y a los que a su vez contribuyó. El primero tiene que ver con la idea de sensibilidad estética como modo de apreciación, y por tanto de conocimiento, ligado a una afectividad adecuada. Este ideal, que hallamos en gran parte del pensamiento estético del XVIII, es próximo a la idea de sentimiento como unión de afecto y entendimiento.

En la sensibilidad estética la emoción aparece siempre matizada, compartiendo un espacio controlado junto al gusto cultivado y el entendimiento. La sensibilidad estética atańe tanto al artista, al que impide caer en el amaneramiento y la sensiblería, como al receptor de la obra, al que aluden los conocidos grabados de Daniel Chodowiecki para el Göttingen Taschenkalendar de 1779, que contraponen el sentimiento natural y el afectado. Schiller se referirá a esa sensibilidad como "un sentimiento vivaz [Regsamkeit des Gefübls]" 26 . La fórmula de la sensibilidad estética encierra en este siglo uno de los modos más claros de asimilación crítica o de exclusión de la emoción: esta no es aceptable como tal si no es integrada bajo el registro o la forma de lo estético, y la sensibilidad propiamente estética nombra principalmente el necesario control sobre una afectividad no medida.

No obstante, aunque es clara la progresiva conquista desde el amplio concepto de conocimiento sensible (Sinnliche Erkenntnis) de Baumgarten hasta una sensibilidad específica de lo estético, la idea de sensibilidad estética cuenta con una valoración muy desigual en los pensadores ilustrados. Están quienes, como Schiller, la

${ }^{26}$ Schiller, F., "Décima carta $\$ 2$ ", en Kallias/Cartas sobre la educación estética del hombre, Barcelona, Anthropos, 1990, p. 183. 
asociarán a una cognición paradigmática, quienes, como dice Menke, la conciban como "la actividad de formación del significado estético" ${ }^{27}$, y están quienes proyecten sobre ella cierta sospecha, como es el caso de Diderot, especialmente en La paradoja del comediante, aunque en este último esté referida al intérprete escénico, no a un receptor genérico. En el primer caso, la emoción está filtrada, inhibida o transportada por el conocimiento, y se enfatiza más su función de significado que de afección; en el segundo, aun apreciándose su acción, no se toma como garantía del arte: "la sensibilidad -dice Diderot- era característica de la bondad del alma y de la mediocridad del genio." ${ }^{28}$

En Diderot la sensibilidad no actúa como garantía de una transposición de la naturaleza en el arte, la sensibilidad artística - del actor en su caso- puede ser tan peligrosa, dice, como la sensibilidad natural. Con esto Diderot inicia una tradición de sospecha hacia ciertos aspectos de la autonomía del arte que alcanzará a Nietzsche. No obstante, lo que sí apreciamos en el crítico de los Salones -y esto es muy importante- es una tajante separación entre la emoción corriente y la expresión artística: esta no implica una afectación real o natural, sino técnica, "con sangre fría" ${ }^{29}$. Tal discontinuidad es sin duda una de las manifestaciones más claras de la escisión entre arte y emoción. Pero en Diderot encontramos también la defensa de una afectividad que sería propia de lo estético, así, distingue Diderot entre quienes se dejan llevar por el sentimiento al oír un relato triste y los que son capaces de juzgar el arte porque poseen "esa emoción delicada en la que el sentimiento no afecta a la comparación." 30 Para él, "ser sensible es una cosa y sentir otra. Lo uno es asunto del alma, lo otro asunto de juicio." 31

Sin duda, es en Schiller donde la sensibilidad estética se presenta más claramente como transfiguradora de la emoción natural. En las Cartas sobre la educación estética del hombre, el sentimiento y la emoción aparecen ligados a lo que Schiller llama el impulso sensible, el de la materia y la vida, opuesto al impulso formal, el de la ley y la forma. Un tercero, el impulso de juego (Spieltrieb) -que vendría a definir lo estéticoligaría y armonizaría aquellos dos impulsos; así, "En la misma medida en que arrebate a las sensaciones y a las emociones [Empfindungen und Affekten] su influencia dinámica, las hará armonizar con las ideas de la razón, y en la misma medida en que prive a las leyes de la razón de su coacción moral, las reconciliará con los intereses

\footnotetext{
${ }^{27}$ Menke, Ch., Die Souveränität der Kunst: Ästhetische Erfahrung nach Adorno und Derrida, Frankfurt am Main, Suhrkamp, 1991, p. 121.

28 Diderot, D., La paradoja del comediante, Madrid, Ediciones del Dragón, 1986, p. 76.

${ }^{29}$ Ibid., p. 34.

${ }^{30}$ Cit. en Becq, A., Genèse de l'esthétique française moderne: de la raison classique à l'imagination créatrice, 16801814, Pisa, Pacini editore, 1984, p. 680.

31 Diderot, D., La paradoja del comediante, op. cit., p. 86.
} 
de los sentidos." ${ }^{32} \mathrm{El}$ arte, desarrollando ese impulso de juego, nivelaría la fuerza de la emoción con la de la forma, y haría desaparecer así toda tendencia a la sensiblería y al sensitivismo, así como todo racionalismo.

Lo estético restituye la unidad de la naturaleza humana de tal forma que el ser humano dominado unilateralmente por sentimientos, y su opuesto, el sujetado unilateralmente por leyes, se unirían en la experiencia de lo bello: "La belleza enlaza los dos estadios contrapuestos del sentir y del pensar." 33 El impulso de juego permite y necesita de la intervención del sentimiento y de la emoción, pero garantiza que estos, como todo aquello que pertenece al impulso sensible, esté siempre armonizado con el impulso formal. No obstante, dice Schiller que el secreto magistral del artista consiste en "aniquilar la materia por medio de la forma" ${ }^{4}$, de manera que cualquier emoción expresada o suscitada está matizada o inhibida por la acción de la forma; la emoción sigue estando, aunque ya trascendida por el juego. "Las artes de la emoción [Künste des Affekts], entre las cuales se halla la tragedia -aclara Schiller-, no son ninguna excepción" ${ }^{35}$, y cuanto más perfectas son más preservan la libertad emocional del espectador.

La emoción es, pues, materia prima del arte, recurso, pero no puede definir el núcleo de lo estético ni de lo artístico: "Hay un arte de la pasión, pero un arte pasional es un contrasentido, porque el infalible efecto de lo bello consiste en liberarnos de las pasiones. [Eine schöne Kunst der Leidenschaft gibt es, aber eine schöne leidenschaftliche Kunst ist ein Widerspruch, denn der unausbleibliche Effekt des Schönen ist Freiheit der Leidenschaften.]" 36 En este punto Schiller recoge la lectura que de la idea aristotélica de catarsis hacen Lessing, Mendelssohn y, más tarde, Schleiermacher.

Nótese que los términos de Schiller parecen menos precisos que los de Kant, en quien es presumible un mayor rigor sistemático. Schiller utiliza fundamentalmente los términos Empfindung y Sinnlichkeit, que tendrían más que ver con una teoría general de la sensación y la sensibilidad. Pocas veces usa el término Gefühl (sentimiento), aunque es significativa la expresión "reinen ästhetischen Gefühl" (sentimiento estético puro ${ }^{37}$, que abre la puerta a la consideración de una afectividad propia y privativa de lo estético.

Por su parte, el término Rührung (emoción) aparece en las Cartas una única vez, de manera significativa además, para aludir a la Juno Ludovisi, el busto de la diosa Hera del que Goethe guardaba una copia: "Capturados y atraídos irresistiblemente

\footnotetext{
32 Schiller, F., "Decimocuarta carta $\$ 6$ ", en Kallias/Cartas sobre la educación estética del hombre, op. cit., p. 229.

33 Schiller, F., "Decimooctava carta $\$ 2$ " Ibid., p. 261.

34 Schiller, F., “Vigesimosegunda carta $\$ 5$ ” Ibid., p. 301.

35 Ídem.

36 Schiller, F., "Vigesimocuarta carta $\$ 5$ " Ibid., p. 303.

37 Schiller, F., "Vigesimosexta carta $\$ 11$ ” Ibid., p. 353.
} 
por la mujer divina, y mantenidos a distancia por la diosa, nos encontramos a la vez en el estado de la máxima serenidad y de la máxima agitación, y nace entonces esa maravillosa emoción [wunderbare Rührung] para la que el entendimiento carece de conceptos y el lenguaje de palabras." ${ }^{38}$ La emoción posee un lugar en la estética schilleriana, pero se trata ya de una emoción específicamente estética, nacida de una feliz entente de la sensibilidad y la razón, de la belleza enérgica y la belleza apacible, de la emoción natural y el entendimiento. Esta confianza representa un aspecto de la emoción no desarrollado por Kant: que ella misma pueda formar parte del proyecto autónomo del arte y de la educación estética siendo generada en esa misma libertad, una emoción hija de la interacción entre la vida y la forma.

Es posible que, en Kallias y en las Cartas, Schiller prefiera hablar en términos de sensación (Empfindung) y sensibilidad (Sinnlichkeit) más que de sentimiento (Gefühl) y emoción (Rührung, Affekt) porque pretenda avanzar hacia un régimen más amplio, que sería el de lo estético, al que pretende dar entidad más allá de los niveles o las experiencias diversas de la afección y la afectividad. Y esto a pesar de que en él las "artes de la emoción" tengan una presencia mucho mayor que en la Crítica del Juicio, como es de esperar en el autor trágico. Por eso en sus primeros escritos sobre la tragedia, procedentes de sus conferencias en el verano de 1790, la emoción $[$ Rührung] aparece claramente singularizada -definida además como "la sensación compuesta del sufrimiento y del placer del sufrimiento" ${ }^{39}$-, pero al hablar de lo estético y de lo artístico en términos más abiertos y generales esta pasa a ser integrada en un impulso sensible armonizado por el impulso de juego.

En Schiller, podríamos decir, lo estético se configura como régimen de sensibilidad estética. Esta alcanza, por tanto, una extensión mayor de la que había tenido en el pensamiento estético del siglo XVIII. La sensación, la afectividad, el sentimiento, la emoción, y también las pasiones, las inclinaciones y los impulsos, se disuelven y transfiguran en un dominio característico, capaz de digerir toda energía y todo impulso, y en el que debe basarse toda educación.

\section{La emoción, entre lo carente de arte y la asimilación romántica}

JUNTO A ESE IDEAL de la sensibilidad estética hay otro desarrollo del kantismo que será igualmente influyente en la estética posterior y en la asimilación problemática de lo emocional. Se trata de la identificación de la emoción con lo carente de arte,

\footnotetext{
38 Schiller, F., “Decimoquinta carta $\$ 9$ ” Ibid., p. 243.

39 Schiller, F., Seis poemas filosóficos y cuatro textos sobre la dramaturgia y la tragedia, Valencia, MuVIM, 2005, p. 129.
} 
tal y como aparece expresado en Schleiermacher: "Lo carente de arte [das Kunstlose] es la inmediata identidad de la excitación y la expresión" ${ }^{40}$, es decir, una conexión directa entre la emoción o la pasión y los tonos o los movimientos del cuerpo. Para Schleiermacher, "Lo carente de arte no tiene medida ni regla (salto de alegría, ira furiosa, grito de horror, etc.) Lo artístico tiene medida y variedad y se convierte en canto y danza." ${ }^{\not 1}$ Lo que da esa medida, lo que media entre la excitación y la expresión es el arquetipo, sin el cual no hay arte. El problema, por tanto, no es la emoción misma, sino la relación que esta guarde con la expresión, que solo es realización -y percepción- artística si ha mediado un arquetipo. La emoción natural se liga a una expresión inmediata en un acto carente de arte; la expresión artística, mediando el arquetipo, mantiene una relación indirecta con aquella emoción y con aquella expresión. Schleiermacher da así un paso más en la escisión diderotiana entre emoción y expresión al aportar la idea de arquetipo y al diferenciar la expresión natural de la expresión artística. El arte es, por tanto, aquella operación que implica una transposición de la afectividad y de la expresividad ligada a ella de forma natural e inconsciente. En 1831 escribirá: "Allí donde es suficientemente fuerte el impulso que transforma en pura representación el perturbado movimiento, pasa a reaccionar retroactivamente sobre sentimientos y ánimos, pues es obvio que el ansia que persigue un fin determinado no está sujeta a dicha ley." ${ }^{42}$

En relación al sentimiento (Gefühl), el padre de la hermenéutica moderna recoge, por una parte, la tradición estética de su siglo y, por otra, la idea de sentimiento de Jacobi, de tal forma que la vinculación entre sentimiento y conocimiento queda reforzada: "En la función cognoscitiva reside el sentimiento, que también es algo cognoscitivo, la conciencia de la relación del hombre con el mundo." ${ }^{43}$ Ahora bien, en el caso de lo artístico, la expresión del sentimiento, como la de la emoción y la pasión, es precisamente aquello "de lo que ha de alejarse el arte" ${ }^{44}$, porque tal sentimiento, aun siendo conocimiento, cuando se da como excitación está ligado a una expresión exterior no "modelada interiormente" ${ }^{45}$. Sólo cuando aparece una fuerza más elevada, una "cognición paradigmática" ${ }^{4}$, se separa la emoción de la expresión natural. Es el momento de la concepción, que modela en el interior algo que pro-

\footnotetext{
${ }^{40}$ Schleiermacher, F. D. E., Estética, Madrid, Verbum, 2004, p. 35 / Schleiermacher, F. D. E., Ästhetik (1832/33) /Über den Begriff der Kunst (1831-33), Hamburg, Felix Meiner Verlag, 2018, p. 11.

${ }^{41}$ Ibid., p. 34 / Ibid., p. 10.

${ }^{42}$ Schleiermacher, F. D. E., "Entusiasmo y cognición paradigmática" (título del antólogo), en Arnaldo, J. (ed.), Fragmentos para una teoría romántica del arte, Madrid, Tecnos, 1994, p. 48.

43 Schleiermacher, F. D. E., Estética, op. cit. p. 34 / Ästhetik (1832/33), op. cit. p. 10.

${ }^{44}$ Ibid., p. 53 / Ibid., p. 34.

${ }^{45}$ Schleiermacher, F. D. E., "Entusiasmo y cognición paradigmática", en Arnaldo, J. (ed.), Fragmentos para una teoría romántica del arte, op. cit., p. 48.

46 Ídem.
} 
cede de una exterioridad -la expresión natural-y que aparece después de nuevo de manera exterior como producción artística. Lo que en Schiller suponía la acción del impulso de juego, es para Schleiermacher la labor de mediación de esa cognición que echa mano de la "formación arquetípica".

En Schleiermacher se perfilan dos líneas que tendrán un claro desarrollo en el siglo XIX. La primera tiene que ver con la ya vista comprensión del sentimiento estético como un sentimiento característico ligado a un modo de conocimiento, idea que también había expresado Goethe en 1772: "Cuando, indiferente a todo lo ajeno, ignorándolo, el arte actúa según ese sentimiento interior, propio, único, independiente, entonces, ya nazca del estado salvaje, ya de una culta sensibilidad, será vital e íntegro." ${ }^{47} \mathrm{Y}$, en los años del Círculo de Jena, el naciente pensamiento romántico consolida la idea de que ese específico sentimiento estético implica necesariamente una transposición de los materiales naturales, si bien, no renuncia a que, a su vez, esta afectividad transfigurada pueda generar nuevos afectos "humanos", diríamos. Así, Friedrich Schlegel llega a afirmar en 1798 que "La esencia del sentimiento poético radica probablemente en que uno puede ser conducido por sí mismo a un estado afectivo, alcanzar el afecto sin un solo apoyo exterior, fantasear sin más.” ${ }^{48}$ Según Schlegel, a Spinoza debemos en gran medida el haber entendido el sentimiento como algo más preciso que la excitabilidad y la pasión ${ }^{49}$. El movimiento romántico asume, por tanto, ese sentimiento específico que filtra y transpone la afectividad natural al ponerla en conexión con los elementos del conocimiento racional, ya sea el significado, la ley o la forma. Esta transposición por medio del sentimiento estético permite, no obstante, la aparición de una nueva afectividad, tan auténtica como la natural pero liberada dentro del arte.

$\mathrm{Al}$ principio de las Lecciones sobre la estética, Hegel presenta la estimulación del ánimo como una de las finalidades del arte, aportando algo diferente: la transposición de realidad que se produce en el arte está basada en una capacidad humana básica según la cual "toda realidad efectiva debe atravesar el medio de la intuición y la representación, y solo a través de este medio penetra en el ánimo y en la voluntad." ${ }^{50}$ En la estética romántica, el interés no está ya puesto en la emoción natural carente de arte que precede a la acción estética o artística, sino en la posterior suscitación de afectividad: "Este despertar de todos los sentimientos en nosotros, este recorrido de nuestro ánimo por todos los contenidos de la vida, la realización

\footnotetext{
${ }^{47}$ Goethe, J. W., "arte característico", en Arnaldo, J. (ed.), Fragmentos para una teoría romántica del arte, op. cit., p. 85 .

48 Schlegel, F., "Fragmentos del Athenäum”, Ibid., p. 144.

49 Schlegel, F., "Alocución sobre la mitología”, Ibid., p. 202.

${ }^{50}$ Hegel, G. W., Lecciones sobre la estética, Madrid, Akal, 2007, p. 38.
} 
efectiva de todas estas conmociones internas mediante una presencia externa solo ilusoria." 51

Sin embargo, aunque en Hegel la emoción suscitada no se diferencia sustancialmente de la corriente (cuando hablamos de ira, compasión, angustia, miedo, etc.), su estética sigue considerando una distinción clara entre las emociones frecuentes y una emoción que sería característica de lo artístico: "[...] una buena cantidad de piezas escénicas recientes que aspiran menos a la poesía que al efecto teatral, y que persiguen, en vez de la emoción verdaderamente poética, la meramente humana." 52

Por otra parte, la afectividad característica del arte aparece en Hegel como pathos, que sería "el auténtico dominio del arte" ${ }^{53}$. Para Hegel ese pathos constituye lo esencial del contenido y la forma de la representación:

Se ha dicho en este sentido que el arte en general debe emocionar [rühren]; pero si este principio debe valer, surge entonces la pregunta esencial por aquello que debiera producir la emoción [Rührung] en el arte. Emoción en general es conmoción [Mitbewegung] como sentimiento, y los hombres, particularmente hoy en día, son en parte fáciles de emocionar. [...]. Pero en el arte sólo debe conmover el pathos en sí mismo verdadero. ${ }^{54}$

También en el romanticismo alemán la emoción ha de enfrentarse de alguna manera a una especificidad de lo artístico; por sí misma no define este ámbito, pero está legitimada en tanto que surge dentro de él. Al igual que en Kant, la emoción es entendida como intensificación o conmoción del sentimiento, pero lo que para el filósofo de Königsberg implicaba una distorsión, aquí es percibido de manera menos problemática al mantener la emoción una línea de filiación con el sentimiento. Si ese sentimiento se da como característico de la experiencia estética y artística, si es "sentimiento estético" o "pathos", entonces, la emoción está justificada.

La segunda línea de desarrollo que partía de Schleiermacher es la que asume la emoción como esa materia bruta que no puede constituirse como tal en lo artístico, que supondría necesariamente una superación, una elaboración y, por tanto, una negación de dicha emoción. Esta idea será recogida directamente por Schopenhauer y por el joven Nietzsche (y esto a pesar de sus críticas y burlas al filósofo silesio): la emoción pertenece al ámbito de la voluntad, contraria al arte. El sentimiento y la emoción, dirá Nietzsche, son "lo no artístico en sí, es más, sólo su completa exclusión es lo que hace posible la total concentración y la contemplación desinteresada del artista." ${ }^{55}$

\footnotetext{
51 Ídem.

52 Ibid., p. 862.

53 Ibid., p. 170.

54 Ídem.

55 Nietzsche, F., Fragmentos póstumos (1869-1874), Volumen I, Madrid, Tecnos, 2010 (FP I 12 [1] Mp XII 1c. Comienzo de 1871), p. 304.
} 
En el joven Nietzsche la primacía del arte sobre la emoción se hace más notoria: no es esta la que se sirve de la música, es la música la que hace uso de la emoción. El afecto en general, sentimiento o emoción, no es el origen de la música y del arte, es solo su objeto. Lo artístico musical integra ahora tal afectividad como símbolo, en tanto que "estos sentimientos sirven para simbolizar la música." ${ }^{56}$ La música es originaria, esto quiere decir que hay algo en el arte que es anterior a la emoción, que la emoción ya no es la materia prima de lo artístico, ni un tipo de experiencia que el arte deba transponer. El arte no es prisma que filtre una emoción natural en bruto, al contrario, es la emoción la que puede simbolizar el arte. De aquí en adelante, la estimación de la emoción por parte de Nietzsche es oscilante ${ }^{57}$.

\section{Conclusión y excurso: las vías de negación de la emoción en el siglo XX}

De la PROBLEMATICIDAD DE LA EMOCIÓN en la estética moderna derivarán principalmente tres vías de negación, exclusión, reducción o transformación de la emoción en la creación artística y el pensamiento estético del siglo XX.

La primera es la que se alza contra el dominio en el arte de la vida psíquica corriente, impuesto por el gusto burgués. Se trata de la confianza vanguardista en la producción por parte del arte de una emoción 'no psicológica'. El nuevo arte, transformador de la realidad y de la vida, toma el ideal nietzscheano del superhombre para transponer y transvalorar las emociones comunes: "En la realidad viviente de lo abstracto -dice Mondrian- el nuevo hombre ha superado los sentimientos de nostalgia, alegría, estremecimiento, dolor, espanto, etc." 58

La abstracción permite ir más allá de la representación de la emoción o del dolor dejando atrás la vía tradicional de reconocimiento-identificación-empatía $a^{59}$. Se desarrolla ahora la vía alternativa del distanciamiento estético -inspirada en la idea kantiana de desinterés- ${ }^{60}$, convertida en programa y en recurso del "teatro épico" de Brecht, opuesto a la vieja dramática aristotélica, en la que aquello que el espectador recibe "no son imágenes de la convivencia humana simplemente, sino escalofríos trágicos. Una especie de masaje para almas perezosas que no hacen suficiente ejercicio en la vida corriente." ${ }^{11}$ Con todo, el arte sigue suscitando emociones, pero estas

\footnotetext{
56 Ídem.

57 Infante del Rosal, F., "Nietzsche y el arte autónomo", en Estudios Nietzsche, n. 14, 2014, pp. 58-59.

58 Mondrian, P., Neue Gestaltung, Munich, Bauhausbücher 5, 1925, p. 8.

59 Vid. Worringer, W., Abstracción y naturaleza. Una contribución a la psicología del estilo, México, FCE, 2008.

${ }^{60}$ Vid. Bullough, E., La distanza psichica come fattore artistico e principio estetico, trad. italiano de G. Compagno, Palermo, Centro Internazionale Studi di Estetica, 1997.

${ }_{61}$ Brecht, B., Escritos sobre teatro, Barcelona, Alba, 2004, p. 93.
} 
ya no tińen con su tono ni desvían con su finalidad la acción del arte, que es ahora más abiertamente política y social.

Dicha vía constituye la asimilación del carácter problemático de la emoción formulado en las estéticas de Kant y Schiller, así como del convencimiento moderno respecto a la acción transfiguradora del sentimiento específicamente estético y artístico.

La segunda vía es aquella que delata la afectividad que ha calado en la expresión hasta el punto de llegar a definir gran parte de las claves de la representación, de las imágenes, de los medios, de las formas artísticas. Esta vía alude a una cierta desafectivización entendida como una superación del subjetivismo romántico y de todas sus marcas estilísticas. Es aquello que Debussy se propone para superar el wagnerianismo. La recuperación propia del teatro de Artaud $^{62}$ de la sensación y del cuerpo, de la vida material por encima de la vida espiritual, pertenece también a esta vía. Otro ejemplo: hablando de la música de cine, Adorno y Eisler afirmaban que "componer música cinematográfica objetiva no significa adoptar a cualquier precio una actitud distante, sino elegir conscientemente la actitud necesaria en cada circunstancia, en lugar de incurrir en clisés o afectaciones musicales." ${ }^{3}$

Esta vía desarrolla la problematicidad de la expresión natural unida a la emoción corriente, tal y como fue formulada por Schleiermacher y recogida posteriormente por Nietzsche, pero su motivación ya no es únicamente la especificidad y autonomía de lo artístico, sino el borrado de los clichés que determinan la asociación recurso-emoción o la adhesión subjetiva incontrolada o inconsciente.

La tercera vía de negación de la emoción es aún más radical, porque parte de la consideración de lo artístico como un ámbito guiado por la especificidad y la autonomía en el que la emoción no puede campar sin devastar ambas cualidades. Es el desarrollo de la idea de un sentimiento específicamente estético capaz de inhibir la emoción no específica: "La emoción estética es una emoción abortada", dice Donald Kuspit ${ }^{64}$.

Con cierta resonancia hegeliana, Adorno expresa de manera tajante esta visión:

El apoyo más firme de la estética subjetiva, el concepto de sentimiento estético, se sigue de la objetividad, no al revés. [...] No se define aristotélicamente mediante la compasión y el miedo, mediante los afectos que se suscitan en el contemplador. La contaminación del sentimiento estético con las emociones psicológicas inmediatas a través del concepto de suscitación ignora la modificación de la experiencia real por la experiencia artística. De lo contrario, sería inexplicable por qué los seres humanos se exponen a la experiencia estética.

$\overline{62}$ Vid. Artaud, A., El teatro y su doble, Barcelona, Edhasa, 1990, pp. 90-91.

63 Adorno, Th. W.; Eisler, H., El cine y la música, Madrid, Fundamentos, 1981, p. 52.

${ }^{64}$ Kuspit, D., El fin del arte, Madrid, Akal, 2006, p. 28. 
El sentimiento estético no es el sentimiento suscitado, sino el asombro ante lo contemplado, ante lo fundamental; lo que se puede llamar sentimiento en la experiencia estética es el avasallamiento por lo no conceptual y empero determinado, no el afecto subjetivo desencadenado. ${ }^{65}$

De estas tres maneras, el arte y el pensamiento del siglo XX prolongan la apreciación moderna de la emoción como hecho problemático dentro de las experiencias estética y artística. Este carácter es constitutivo de lo estético tal y como es configurado en la Modernidad y ninguna fórmula moderna o contemporánea puede darse sin referirse de alguna manera a él.

${ }_{65}$ Adorno, Th. W., Teoría estética, (Obra completa, 7), Madrid, Akal, 2004, p. 220. 


\section{REFERENCIAS Bibliográficas}

Adorno, Th. W., Teoría estética, (Obra completa, 7), Madrid, Akal, 2004.

Adorno, Th. W.; Eisler, H., El cine y la música, Madrid, Fundamentos, 1981.

Arnaldo, J. (ed.), Fragmentos para una teoría romántica del arte, Madrid, Tecnos, 1994.

Artaud, A., El teatro y su doble, Barcelona, Edhasa, 1990.

Becq, A., Genèse de l'esthétique française moderne: de la raison classique à l'imagination créatrice, 1680-1814, Pisa, Pacini editore, 1984

Brecht, B., Escritos sobre teatro, Barcelona, Alba, 2004.

Bourdieu, P., La distinción. Criterios y bases sociales del gusto, Madrid, Taurus, 2016.

Bullough, E., La distanza psichica come fattore artistico e principio estetico, trad. italiano de G. Compagno, Palermo, Centro Internazionale Studi di Estetica, 1997.

Cheetham, Mark A., Kant, Art, and Art History: Moments of Discipline, New York, Cambridge University Press, 2001.

Diderot, D., La paradoja del comediante, Madrid, Ediciones del Dragón, 1986.

González, A. M., "Emoción, Sentimiento y Pasión en Kant", en Trans/Form/ Ação vol.38, n.3 Marília sept./dec. 2015, pp. 75-98. doi.org/10.1590/S010131732015000300006

Hegel, G. W., Lecciones sobre la estética, Madrid, Akal, 2007.

Infante del Rosal, F., "Nietzsche y el arte autónomo", en Estudios Nietzsche, n. 14, 2014, pp. 47-61.

Kant, I., Beobachtungen über das Gefühl des Schönen und Erhabenen (GSE), en Gesammelte Schriften, Berlin, Preussische Akademie der Wissenschaften (vol. 02), 1912.

Kant, I., Crítica del juicio, trad. M. G. Morente, Madrid, Austral, 1999.

Kant, I.; Crítica del discernimiento, trad. Aramayo y Mas, Madrid, Antonio Machado, 2019.

Kant, I., Kritik der Urteilschaft, Köln, Anaconda Verlag, 2015 (asimilada a Gesammelte Schriften, Berlin, Preussische Akademie der Wissenschaften, vol. 1-22). 
Kant, I., "Praktische Philosophie Powalski", en Gesammelte Schriften, Berlin, Preussische Akademie der Wissenschaften (vol. 1-22); Deutsche Akademie der Wissenschaften (vol. 23); Göttingen y Berlin, Akademie der Wissenschaften (vol. 24 y ss.), 1900.

Kant, I., Observaciones sobre el sentimiento de lo bello y lo sublime, Madrid, Fondo de Cultura Económica, 2005.

Kuspit, D., El fin del arte, Madrid, Akal, 2006.

Menke, Ch., Die Souveränität der Kunst: Ästhetische Erfahrung nach Adorno und Derrida, Frankfurt am Main, Suhrkamp, 1991.

Mondrian, P., Neue Gestaltung, Munich, Bauhausbücher 5, 1925.

Nietzsche, F., Fragmentos póstumos (1869-1874), Volumen I, Madrid, Tecnos, 2010.

Park, K. H., Kant über das Erhabene: Rekonstruktion und Weiterführung der kritischen Theorie des Erhabenen Kants, Würzburg, Königshausen and Neumann, 2009.

Rancière, J., El malestar en la estética, Madrid, Clave Intelectual, 2012.

Schiller, F., Kallias/Cartas sobre la educación estética del hombre, (bilingüe), Barcelona, Anthropos, 1990.

Schiller, F., Seis poemas filosóficos y cuatro textos sobre la dramaturgia y la tragedia, Valencia, MuVIM, 2005.

Schleiermacher, F. D. E., Estética, Madrid, Verbum, 2004.

Schleiermacher, F. D. E., Ästhetik (1832/33) / Über den Begriff der Kunst (183133), Hamburg, Felix Meiner Verlag, 2018.

Shiner, L., La invención del arte, Barcelona, Paidós, 2004.

Worringer, W. (1908): Abstracción y naturaleza. Una contribución a la psicología del estilo, México, Fondo de Cultura Económico, 2008.

DOI: https://doi.org/10.15366/bp.2020.24.018

Bajo Palabra. II Época. № 24. Pgs: 361-384 
$384-$ 